\title{
Increased blood velocities in the heart and great vessels of patients with congenital heart disease An assessment of their significance in the absence of valvar stenosis
}

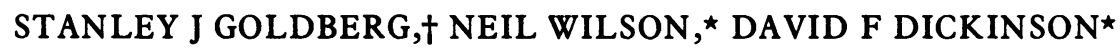 \\ From the ${ }^{\star}$ Non-Invasive Unit, Killingbeck Hospital, Leeds, and the †University of Arizona, Tucson, Arizona, USA
}

SUMMARY During a previous investigation and during routine clinical Doppler echocardiography velocities distal to normal valves were found to be increased in patients with congenital heart disease. To investigate this observation the velocity proximal and distal to cardiac valves was recorded in 56 patients with congenital heart disease. No detectable pressure gradient had been found across these valves at catheterisation and no velocity gradient $>20 \mathrm{~cm} / \mathrm{s}$ was found across them by range gated Doppler echocardiography. In $82 \%$ of the patients, however, the blood velocity across one or more valves exceeded normal limits. Increased velocities were found at the tricuspid inflow (55\%), pulmonary artery $(38 \%)$, mitral inflow $(34 \%)$, and ascending aorta $(11 \%)$. Factors predisposing to the presence of increased velocities in these areas were increased flow through the valve and decreased compliance of the receiving chamber.

This study shows the necessity for recording velocity both proximal and distal to a valve before a gradient is calculated according to the modified Bernouilli equation.

Doppler interrogation of velocities in the heart and great vessels is now an accepted diagnostic procedure. Previous physical,' angiographic, ${ }^{2}$ and Doppler investigations ${ }^{3}$ have shown that flow through stenotic valves produces a jet and that the velocity of the jet is related to the magnitude of the pressure gradient, which may be calculated using a modification of the Bernouilli equation. ${ }^{45}$ This modified formula is as follows: pressure gradient $=4\left(\mathrm{~V}^{2}-\mathrm{V}^{2}\right)$ where $\mathrm{V} 2$ is the velocity $(\mathrm{m} / \mathrm{s})$ distal to the valve and $\mathrm{Vl}$ is the velocity $(\mathrm{m} / \mathrm{s})$ proximal to the valve.

In practice, however, it is usual to ignore the proximal velocity because its inclusion would not have a major influence on the result. Accordingly, most increased velocities are assumed to be due to stenosis, and a gradient is calculated on the basis of the increased distal velocity alone.

Requests for reprints to Dr D F Dickinson, Non-Invasive Unit, Killingbeck Hospital, York Road, Leeds LS14 6UQ.

Accepted for publication 31 January 1985
During the course of many clinical Doppler examinations of children with congenital heart defects, we found that some patients without stenotic lesions had velocities in the central circulation that exceeded values found in normal populations. The purpose of this investigation was to identify situations in which these increased values might be expected.

\section{Patients and methods}

The study population consisted of those patients with congenital heart disease studied by Doppler echocardiography in Killingbeck Hospital between February and May 1984 who met the following criteria: $(a)$ confirmation of diagnosis by cardiac catheterisation (except in the case of those patients with an isolated ductus arteriosus who were normal on physical examination after ligation, $(b)$ measurement of pressure proximal and distal to all valves at cardiac catheterisation, and $(c)$ no significant difference in blood velocity or pressure measurement across the valve of interest. Several patients with stenotic valves were included (Table), but the velocity across the 
Table Peak velocity measurements of blood flow distal to each valve

\begin{tabular}{|c|c|c|c|c|c|c|}
\hline \multirow{2}{*}{$\begin{array}{l}\text { Case } \\
\text { No }\end{array}$} & \multirow{2}{*}{$\begin{array}{l}\text { Age } \\
(y r)\end{array}$} & \multirow[t]{2}{*}{ Diagnosis } & \multicolumn{4}{|c|}{ Postvalve velocity $(\mathrm{cm} / \mathrm{s})$} \\
\hline & & & Tricuspid & Mitral & Pulmonary & Aortic \\
\hline $\begin{array}{r}1 \\
2 \\
3 \\
4 \\
5 \\
6 \\
7 \\
8 \\
9 \\
10 \\
11 \\
12 \\
13 \\
14 \\
15 \\
16 \\
17 \\
18 \\
19 \\
20 \\
21 \\
22 \\
23\end{array}$ & $\begin{array}{c}9 \\
7 \\
2 \\
4 \\
8 \\
7 \\
8 \\
29 \\
0 \cdot 4 \\
2 \\
4 \\
14 \\
7 \\
8 \\
8 \\
15 \\
1 \\
2 \\
7 \\
0.9 \\
1 \\
0 \cdot 6 \\
15\end{array}$ & $\begin{array}{l}\text { Aortic stenosis } \\
\text { Aortic stenosis } \\
\text { Aortic stenosis } \\
\text { Aortic stenosis } \\
\text { Aortic stenosis } \\
\text { Aortic stenosis } \\
\text { Aortic stenosis } \\
\text { Aortic stenosis } \\
\text { Aortic stenosis, coarctation of aorta } \\
\text { Aortic stenosis, coarctation of aorta } \\
\text { Atrial septal defect } \\
\text { Atrial septal defect } \\
\text { Atrial septal defect } \\
\text { Atrial septal defect } \\
\text { Atrial septal defect } \\
\text { Atrial septal defect } \\
\text { Atrial septal defect } \\
\text { Atrial septal defect } \\
\text { Atrial septal defect } \\
\text { Atrial septal defect, pulmonary hypertension } \\
\text { Complete transposition, postoperative } \\
\text { Complete transposition } \\
\text { Complete transposition, ventricular septal defect, } \\
\text { pulmonary stenosis, postoperative }\end{array}$ & $\begin{array}{r}50 \\
35 \\
70 \\
30 \\
72 \\
62 \\
40 \\
42 \\
45 \\
42 \\
86 \\
84 \\
105 \\
92 \\
79 \\
90 \\
150 \\
78 \\
118 \\
136 \\
80 \\
65 \\
109\end{array}$ & $\begin{array}{r}105 \\
105 \\
122 \\
136 \\
68 \\
114 \\
130 \\
142 \\
120 \\
140 \\
66 \\
75 \\
80 \\
82 \\
85 \\
90 \\
92 \\
122 \\
108 \\
105 \\
62 \\
60 \\
108\end{array}$ & $\begin{array}{c}65 \\
90 \\
82 \\
70 \\
68 \\
98 \\
48 \\
96 \\
78 \\
65 \\
78 \\
236 \\
155 \\
120 \\
102 \\
170 \\
\text { Jet } \\
148 \\
160 \\
110 \\
\text { Jet } \\
90 \\
\text { Jet }\end{array}$ & $\begin{array}{c}\text { Jet } \\
\text { Jet } \\
\text { Jet } \\
\text { Jet } \\
\text { Jet } \\
\text { Jet } \\
\text { Jet } \\
\text { Jet } \\
\text { Jet } \\
\text { Jet } \\
150 \\
102 \\
125 \\
108 \\
100 \\
130 \\
106 \\
102 \\
109 \\
105 \\
50 \\
90 \\
104\end{array}$ \\
\hline $\begin{array}{l}24 \\
25 \\
26 \\
27 \\
28 \\
29 \\
30 \\
31 \\
32 \\
33 \\
34 \\
35 \\
36 \\
37 \\
38 \\
39 \\
40 \\
41 \\
42 \\
43 \\
44 \\
45 \\
46 \\
47 \\
48 \\
49 \\
50 \\
51 \\
52 \\
53 \\
54 \\
55 \\
56\end{array}$ & $\begin{array}{l}3 \\
0.6 \\
3 \\
10 \\
1 \\
6 \\
0 \cdot 1 \\
2 \\
5 \\
5 \\
0 \cdot 5 \\
1 \\
7 \\
2 \\
2 \\
0 \cdot 8 \\
0 \cdot 3 \\
0 \cdot 1 \\
4 \\
4 \\
1 \\
4 \\
3 \\
4 \\
29 \\
25 \\
4 \\
10 \\
0 \cdot 4 \\
1 \\
5 \\
0.3 \\
0.1\end{array}$ & $\begin{array}{l}\text { Atrioventricular septal defect } \\
\text { Atrioventricular septal defect, persistent ductus arteriosus } \\
\text { Parachute mitral valve } \\
\text { Persistent ductus arteriosus } \\
\text { Persistent ductus arteriosus } \\
\text { Persistent ductus arteriosus } \\
\text { Persistent ductus arteriosus } \\
\text { Persistent ductus arteriosus } \\
\text { Pulmonary stenosis } \\
\text { Pulmonary stenosis } \\
\text { Pulmonary stenosis } \\
\text { Pulmonary stenosis, atrial septal defect } \\
\text { Systemic hypertension } \\
\text { Tricuspid atresia } \\
\text { Total anomalous pulmonary venous connection } \\
\text { Complete transposition, postoperative } \\
\text { Complete transposition, postoperative } \\
\text { Complete transposition, postoperative } \\
\text { Tetralogy of Fallot } \\
\text { Tetralogy of Fallot } \\
\text { Tetralogy of Fallot } \\
\text { Tetralogy of Fallot } \\
\text { Tetralogy of Fallot } \\
\text { Tetralogy of Fallot } \\
\text { Tetralogy of Fallot, pulmonary incompetence, postoperative } \\
\text { Tetralogy of Fallot, pulmonary incompetence, postoperative } \\
\text { Tetralogy of Fallot, pulmonary incompetence, postoperative } \\
\text { Ventricular septal defect } \\
\text { Ventricular septal defect } \\
\text { Ventricular septal defect, pulmonary hypertension } \\
\text { Ventricular septal defect, pulmonary stenosis } \\
\text { Ventricular septal defect, pulmonary hypertension } \\
\text { Ventricular septal defect, pulmonary stenosis }\end{array}$ & $\begin{array}{r}88 \\
140 \\
62 \\
65 \\
42 \\
46 \\
68 \\
65 \\
34 \\
54 \\
55 \\
140 \\
105 \\
89 \\
112 \\
95 \\
100 \\
85 \\
80 \\
78 \\
94 \\
65 \\
102 \\
88 \\
95 \\
113 \\
64 \\
60 \\
92 \\
70 \\
80 \\
102\end{array}$ & $\begin{array}{r}98 \\
140 \\
\text { Jet } \\
82 \\
102 \\
131 \\
136 \\
150 \\
60 \\
76 \\
82 \\
65 \\
142 \\
130 \\
90 \\
60 \\
80 \\
80 \\
50 \\
60 \\
62 \\
78 \\
80 \\
100 \\
94 \\
52 \\
88 \\
116 \\
120 \\
120 \\
52 \\
120 \\
118\end{array}$ & $\begin{array}{c}158 \\
194 \\
76 \\
105 \\
92 \\
70 \\
\text { Jet } \\
120 \\
\text { Jet } \\
\text { Jet } \\
\text { Jet } \\
\text { Jet } \\
106 \\
40 \\
210 \\
\text { Jet } \\
100 \\
140 \\
\text { Jet } \\
\text { Jet } \\
\text { Jet } \\
\text { Jet } \\
\text { Jet } \\
\text { Jet } \\
92 \\
132 \\
120 \\
160 \\
78 \\
120 \\
\text { Jet } \\
103 \\
\text { Jet }\end{array}$ & $\begin{array}{r}106 \\
140 \\
140 \\
135 \\
204 \\
161 \\
205 \\
205 \\
108 \\
116 \\
80 \\
84 \\
145 \\
98 \\
120 \\
70 \\
100 \\
106 \\
80 \\
80 \\
80 \\
90 \\
70 \\
112 \\
68 \\
72 \\
102 \\
118 \\
120 \\
116 \\
60 \\
120 \\
70\end{array}$ \\
\hline
\end{tabular}

Jet, high velocity flow associated with valvar stenosis.

stenotic valve was not of interest to this study. For example, a child with known pulmonary valvar stenosis was included if all three criteria were satisfied, but the pulmonary velocity was not included in this study. Nevertheless, velocities proximal and distal to the other three valves were appropriate to the interests of this study.

\section{ECHOCARDIOGRAPHY}

A complete cross sectional echocardiographic and range gated Doppler examination was performed on each patient. ${ }^{6}$ Mitral and tricuspid velocities were measured in the apical four chamber plane according to previously described techniques. ${ }^{7}$ The sample volume was initially placed distal to the valve and was 


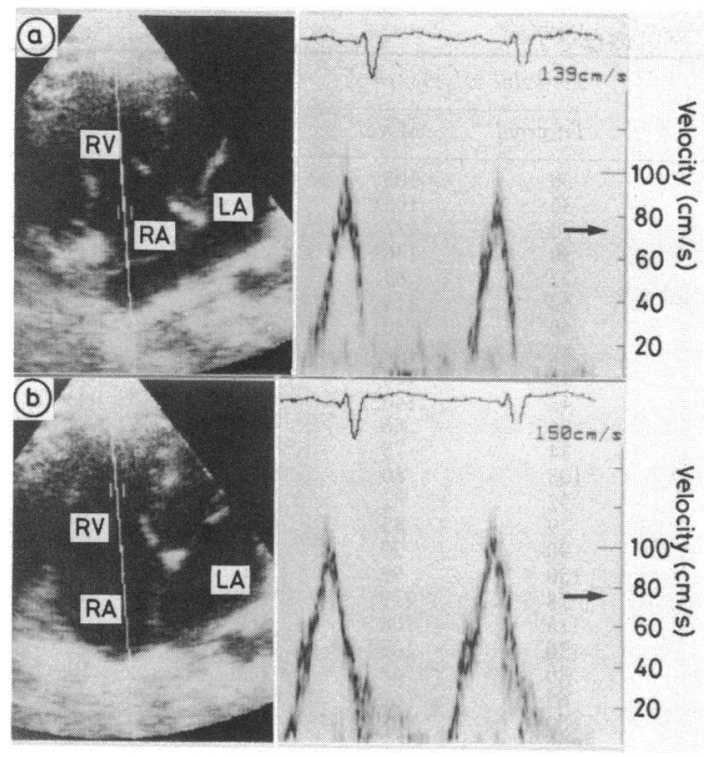

Figure Cross sectional echocardiogram and time-velocity trace in a patient with pulmonary stenosis. The alignment of the ultrasound beam is shown by a highlighted line passing from the right ventricle $(R V)$ to the right atrium $(R A)$. The arrow indicates the upper limit of tricuspid velocity in normal individuals $(77 \mathrm{~cm} / \mathrm{s})$. The sample volume for Doppler recording is shown as two short lines astride the Doppler cursor line (a) just proximal to the tricuspid valve leaflets and (b) just distal to the tricuspid valve leaflets. The velocity trace shows blood flow at a velocity slightly higher but still within $20 \mathrm{~cm} / \mathrm{s}$ of the velocity proximal to the valve.

aligned with the expected direction of flow as determined from the cross sectional echocardiographic image. The transducer was then moved in the plane of that image to achieve the highest velocity and the least spectral broadening, which occur concurrently when alignment with flow is achieved. After that location was identified the transducer was moved in the unseen (elevational) plane to maximise velocity and to minimise spectral broadening. This process allowed spatial alignment with flow. Accordingly, no correction was necessary for the intercept angle between the ultrasound beam and the direction of blood flow. Velocity distal to the valve was then recorded. Finally, the sample volume was placed proximal to the valve and the spatial alignment procedure repeated. The proximal and distal velocities were compared taking a mean of three to five cardiac cycles in each case. If the modal peak velocity for the two measurements was within $20 \mathrm{~cm} / \mathrm{s}$ no true velocity difference was considered to be present across the valve. The process for measurement of velocities across the semilunar valves was similar, but different planes of ultrasound examination were used. Velocities across the pulmonary valve were studied from a high precordial short axis plane and velocities across the aortic valve were measured with an off axis imaging transducer from a short axis position in the suprasternal notch. ${ }^{7}$ This transducer permits Doppler interrogation of the ascending aorta and left ventricular outflow tract parallel to blood flow. The spatial alignment with flow direction was accomplished in these planes according to the same method described for the atrioventricular valves.

\section{Results}

\section{STUDY POPULATION}

During the study period 482 patients with congenital heart disease underwent Doppler studies at Killingbeck Hospital. Four hundred and twenty four patients were excluded because $(a)$ they had not undergone cardiac catheterisation (the most common reason) or (b) they had undergone catheterisation but did not have a measurement of pressure across the valve(s) of interest or, in a few instances, because a complete Doppler study was not or could not be performed. Fifty eight patients met the criteria for inclusion into the study. We were, however, unable to align satisfactorily with flow proximal to the aortic valve in two patients, who were then excluded. Accordingly, 56 patients formed the study group.

\section{DOPPLER ECHOCARDIOGRAPHY}

Measurement of velocity proximal and distal to the atrioventricular valves presented no problem. Alignment with the left ventricular outflow tract required the beam to be directed more anteriorly than is usual to image the ascending aorta. Although satisfactory results could be obtained for all but two patients, some experienced mild discomfort. The major problem was that the pressure of the transducer on the larynx caused some patients to cough almost continuously when the transducer was in position to image the outflow tract; severe paroxysms of coughing resulted in the exclusion of the two patients mentioned above. Interrogation of the pulmonary outflow tract and main pulmonary artery presented, in a few patients, a problem of beam-flow intercept angle. Although it was possible to achieve alignment with flow in the main pulmonary artery, an intercept angle as large as $30^{\circ}$ was occasionally found at the level of the pulmonary valve. Although it was easy to determine the presence or absence of a velocity difference by sampling immediately proximal and distal to the valve, the absolute velocity measured at this site was less than in the centre of the distal main pulmonary artery because the intercept angle was less favourable at the valve than at the centre of the main pulmonary artery. 


\section{PREVALENCE OF VELOCITIES EXCEEDING} NORMAL

To determine which velocities exceeded normal, we used the data previously collected in this unit by the same techniques. ${ }^{8}$ Values exceeding the mean by 2 standard deviations or more were considered abnormal. The upper limits of normal velocity distal to the four cardiac valves were: tricuspid $77 \mathrm{~cm} / \mathrm{s}$, pulmonary $115 \mathrm{~cm} / \mathrm{s}$, mitral $109 \mathrm{~cm} / \mathrm{s}$, and aortic $142 \mathrm{~cm} / \mathrm{s}$. The Figure shows an example of a velocity in excess of normal. When jet velocities were excluded only 10 of $56(18 \%)$ patients had all other velocities within the normal range (Table).

\section{Increased tricuspid velocities}

Thirty one of 55 (56\%) had tricuspid velocities in excess of the normal range. Most patients with normal tricuspid velocities had lesions affecting mainly the left heart: aortic stenosis (10), parachute mitral valve (one), persistent ductus (five). Many patients with a variety of other lesions also had normal velocities. The common features of those with increased velocities (with the single exception of case No 36, Table) were either the presence of $(a)$ lesions associated with increased right heart flow-atrial septal defect (10), atrioventricular defects (two), and pulmonary regurgitation (three); or $(b)$ lesions causing increased resistance to flow into the right ventricle-tetralogy of Fallot (five), pulmonary stenosis (one), complete transposition (five), and ventricular septal defect associated with pulmonary hypertension (three) or with pulmonary stenosis (one).

\section{Increased pulmonary velocities}

All 17 patients with pulmonary jets were excluded from consideration. Fifteen of the remaining 39 (38\%) had increased pulmonary velocities. All of these patients had either increased pulmonary blood flow due to left to right shunts (13/15) or pulmonary valve regurgitation (2/15). Nevertheless, 10 of the 24 who had normal pulmonary artery velocities also had increased pulmonary flow. Twelve of the remaining 14 with normal pulmonary velocities had left sided obstructive lesions-aortic stenosis (10), parachute mitral valve (one), or systemic hypertension (one).

\section{Increased mitral velocities}

All but one (case 18, Table) of the 19 patients with increased mitral velocity had lesions that caused increased mitral flow-ventricular septal defect (five), ductus arteriosus (four), tricuspid atresia (one)-or defects which caused aortic outflow obstructionaortic stenosis with or without coarctation (seven), and systemic hypertension (one). Normal mitral velocities were found in a variety of conditions- tetralogy (nine), atrial septal defect of the secundum or endocardial cushion type (11), complete transposition (six), pulmonary stenosis (four), ventricular septal defect (two), ductus arteriosus (two), and aortic stenosis (three).

\section{Increased aortic velocities}

Six patients $(11 \%)$ had increased aortic velocities, and only four of these were increased by more than $10 \%$. All patients with a more than $10 \%$ increase had increased aortic flow due to a ductus arteriosus. Two others had minor increases, one with systemic hypertension and one with an atrial septal defect. All remaining patients, including one with increased aortic flow due to a ductus arteriosus, had velocities within the normal range.

\section{Discussion}

The important finding of this investigation is that many children with congenital cardiac malformations have blood velocities that exceed normal limits at sites within the heart that do not contain stenotic lesions. Accordingly, erroneous conclusions might be reached if velocities distal to the valve were used exclusively to calculate pressure gradients according to the modified Bernouilli equation. If the velocities proximal to the valves were neglected, the range of postvalve velocities found in many of our patients would have led to the erroneous identification of stenotic lesions albeit of a relatively minor degree. Strong evidence that the increased distal velocities in this population were not due to stenotic lesions is shown by the presence of equal or nearly equal velocities proximal and distal to the valve of interest. The results of this study clearly show that high velocity alone is not an indicator of valvar stenosis. We allowed a mean peak velocity difference of $20 \mathrm{~cm} / \mathrm{s}$ between the two sites before a stenosis was considered to be present because this value was the highest velocity difference across a valve observed while studying a normal group.

The patient group was neither representative of the general population nor of the total population of children with cardiac malformations because, with the exception of those with a ductus arteriosus, all were selected for cardiac catheterisation. Accordingly, it is probable that a different percentage of individuals with increased velocities would be found in a different population. The important finding, however, is the existence of increased velocities rather than a measure of their precise occurrence rate.

Two factors, increased flow and increased resistance to flow, were associated with increased peak velocity. Other, as yet unidentified, factors may also exist. Increased flow has been mentioned by Hatle and Angelsen as a cause of increased velocity, ${ }^{9}$ and we 
have reported data from a small series of patients with ductus arteriosus that substantiates this. ${ }^{10}$ The finding is not surprising because velocity must increase when a higher than normal volume is delivered through a conduit or orifice of fixed dimension assuming that all other factors remain unchanged. The present investigation was not designed to determine the relation between peak velocity and flow because two other factors, the area through which flow passes and systolic time per beat, are also important in determining the peak velocity for any given flow rate.

Mitral and aortic velocity almost always exceed tricuspid and pulmonary velocity in the normal subject. ${ }^{89}$ This finding has been attributed to the relatively decreased distensibility of the left ventricle and systemic circulation compared with that of the right ventricle and pulmonary circulation. We are not, however, aware of any previous reports regarding the requirement of increased velocities to fill ventricles or vascular beds characterised by decreased compliance. Our findings in this respect remain descriptive because the present investigation was not designed to determine the precise magnitude of peak velocity required to distend a chamber or vascular bed of reduced compliance at a given flow. Such a study would not be possible on the basis of gradient or wall thickness alone.

Pressures across valves were measured at catheterisation using fluid filled catheters and pullback tracings rather than with two catheters with pressure manometers mounted at their tips. Accordingly, some small gradients could have been missed. Our Doppler methodology allowed a difference in velocity between the areas proximal and distal to the valve of $20 \mathrm{~cm} / \mathrm{s}$. This velocity difference could account for a pressure gradient of $1-4 \mathrm{~mm} \mathrm{Hg}$ depending on whether it occurred at the lowest or highest measured velocity. It seems unlikely that large gradients were missed by either method. Clearly, however, some patients with postvalvar velocities similar to those in the study had catheterisation and Doppler determined pressure gradients, sometimes called flow gradients, but these patients were excluded from this study by design because we were concerned only with those patients who had an increased postvalve velocity in the absence of a measured pressure gradient.

Some patients with increased flows or suspected decreased compliance had normal velocities. In these patients alterations in other factors-for example, conduit or orifice dimension or a long systolic time-may have permitted lower velocities. Nevertheless the results suggest that increased velocities are often required to accommodate high flow rates and decreased compliance.

\section{References}

1 Kececioglu-Draelos Z, Goldberg SJ, Aréias J, Sahn DJ. Verification and clinical demonstration of the echo Doppler series effect and vortex shed distance. Circulation 1981; 63: 1422-8.

2 Simon AL, Reis RL. The angiographic features of bicuspid and unicommissural aortic stenosis. Am $\mathcal{F}$ Cardiol 1971; 28: 353-8.

3 Stevenson JG, Kawabori I, Dooley T, Guntheroth WG. Diagnosis of ventricular septal defect by pulsed Doppler echocardiography. Sensitivity, specificity and limitations. Circulation 1979; 58: 322-6.

4 Hatle L. Noninvasive assessment and differentiation of left ventricular outflow obstruction with Doppler ultrasound. Circulation 1981; 64: 381-7.

5 Holen J, Aasliid R, Landmark K, Simonsen S. Determination of pressure gradient in mitral stenosis with a noninvasive ultrasound Doppler technique. Acta Med Scand 1976; 199: 455-60.

6 Goldberg SJ, Allen HD, Marx GR, Flinn CJ. Doppler echocardiography. Philadelphia: Lea and Febiger, 1985: 26-53.

7 Loeber CP, Goldberg SJ, Allen HD. Doppler echocardiographic comparison of flows distal to the four cardiac valves. 7 Am Coll Cardiol 1984; 4: 268-72.

8 Wilson N, Goldberg SJ, Dickinson DF, Scott O. Normal intracardiac and great artery blood velocity measurements by pulsed Doppler echocardiography. Br Heart $\mathcal{F}$ 1985; 53: 451-8.

9 Hatle L, Angelsen B. Doppler ultrasound in cardiology. Philadelphia: Lea and Febiger, 1982: 146.

10 Wilson N, Dickinson DF, Goldberg SJ, Scott O. Pulmonary artery velocity patterns in ductus arteriosus. $\mathrm{Br}$ Heart f 1984; 52: 462-4. 